\title{
Os efeitos dos movimentos rurais e das oportunidades políticas na construção do programa de compras governamentais do Rio Grande do Norte
}

DOI: 10.36920/esa-v29n3-9

(iD)
Joana Tereza Vaz de Moura ${ }^{1}$
Winifred nnox $^{2}$
iD Marcos Aurélio Freire da Silva Júnior ${ }^{3}$

Resumo: O artigo tem como objetivo compreender o papel dos efeitos políticos dos movimentos sociais na elaboração e aprovação do Programa Estadual de Compras Governamentais da Agricultura Familiar e Economia Solidária (Pecafes) no Rio Grande do Norte. Buscamos dialogar com a literatura sobre os resultados das ações dos movimentos sociais para as políticas públicas. Partimos da hipótese de que os movimentos sociais aproveitaram a oportunidade política das eleições de 2018 no RN para propor uma política de acesso aos mercados institucionais. A metodologia é essencialmente qualitativa. Foram realizadas entrevistas com as principais lideranças dos movimentos rurais e com representantes do governo, além das análises dos discursos e narrativas dos atores nas audiências públicas e em jornais e revistas e de documentos. Os resultados mostram que três fatores foram essenciais para que os movimentos sociais conseguissem pautar a política: o histórico de organização desses movimentos no estado garantindo uma pauta propositiva bem definida; a janela de oportunidade política criada por um governo aberto aos movimentos sociais; e, por fim, a não identificação de pontos de veto ao programa na Assembleia Legislativa.

Palavras-chave: movimentos sociais rurais; efeitos políticos; políticas públicas; programa de compras governamentais; oportunidades políticas.

\begin{abstract}
The influence of rural movements and political opportunities in the construction of the government procurement program in Rio Grande do Norte). The article examines the role of the political influence of social movements in the elaboration and approval of the State
\end{abstract}

\footnotetext{
${ }^{1}$ Professora do Departamento de Políticas Públicas do Centro de Ciências Humanas, Letras e Artes da Universidade Federal do Rio Grande do Norte (UFRN). Pós-doutora em Sociologia pela New York University (NYU). Doutora em Ciência Política pela Universidade Federal do Rio Grande do Sul (UFRGS). E-mail: joanatereza@gmail.com.

${ }^{2}$ Professora do Departamento de Políticas Públicas do Centro de Ciências Humanas, Letras e Artes da Universidade Federal do Rio Grande do Norte (UFRN). Doutora em Ciências Sociais pela Universidade Federal do Rio Grande do Norte (UFRN). E-mail: winknox@gmail.com.

${ }^{3}$ Mestre pelo Programa de Pós-graduação em Estudos Urbanos e Regionais da Universidade Federal do Rio Grande do Norte (UFRN). E-mail: marcosaureliojunior@gmail.com.
} 
Program for Government Procurement of Family Farming and Solidarity Economy (PECAFES) in Rio Grande do Norte. For this purpose, a dialogue is established with the literature on the impact of the actions of social movements on public policies. The initial hypothesis was that social movements took advantage of the political opportunity of the 2018 elections in RN to propose a policy of access to institutional markets. The question, therefore, became, how was it possible for this policy to enter the government agenda and have unanimous approval in the legislative assembly? The methodology adopted is essentially qualitative. Interviews were carried out with the main leaders of the rural movements and with government representatives, in addition to analysing the speeches and narratives of the actors in public hearings and in newspapers and magazines, together with other relevant documents. The results show that three factors were essential for the social movements to be able to promote this policy: these movements' history of organization in the state, guaranteeing a well-defined proactive agenda; the window of political opportunity created by a government open to social movements; and, finally, the non-identification of veto points to the program in the Legislative Assembly.

Keywords: rural social movements; political impacts; public policies; government procurement programs; political opportunities.

\section{Introdução}

Especialmente a partir dos anos 1990, temos acompanhado a vasta produção acadêmica sobre as interações socioestatais no âmbito das ciências sociais brasileiras. A maioria dos estudos desenvolvidos ao longo dos anos 1990 e início dos anos 2000 buscou compreender as ações de organizações da sociedade civil nas chamadas instituições participativas (IPs) e a efetividade desses espaços. Os conselhos gestores e os orçamentos participativos se tornaram lócus de análise de uma miríade de pesquisas acadêmicas e tiveram como "foco das atenções [...] [as] modalidades de participação da sociedade civil e dos seus impactos na criação de novas instituições que teriam potencial para conferir maior legitimidade, justiça e eficácia às decisões políticas” (ALMEIDA; TATAGIBA, 2012, p. 70).

Dessa agenda de pesquisa, foram muitos os resultados relevantes para a compreensão da importância dessas inovações participativas, mas também dos seus desafios, tanto para os gestores públicos quanto para os movimentos sociais. Com a eleição do ex-presidente Luiz Inácio Lula da Silva, em 2002, novos repertórios de interação entre Estado e sociedade foram impulsionados, possibilitando a construção e o fortalecimento de espaços participativos. Conforme destacam Abers, Serafim e Tatagiba (2014, p. 326), “no governo Lula, o mote da 'participação da sociedade' abriu espaço para a combinação mais criativa de diferentes práticas e rotinas, ampliando as 
chances de acesso e influência dos movimentos sobre o Estado". As análises trouxeram conceitos importantes, como o de ativismo institucional, para explicitar a entrada de militantes na burocracia estatal, buscando pautar "os objetivos do movimento social através de canais burocráticos convencionais" (RECH; SILVA, 2016, p. 375).

Desses estudos e avanços na literatura dos movimentos sociais, podemos observar que, no geral, eles, assim como nós, procuravam compreender como o engajamento de movimentos sociais, ativistas e organizações da sociedade civil podem contribuir para a formulação e implementação das políticas públicas. As políticas públicas são produtos da decisão dos gestores públicos, podendo ou não virem alinhadas às pautas das demandas da sociedade civil. Segundo Dowbor, Carlos e Albuquerque (2018, p. 48), mesmo havendo certo consenso na literatura sobre a importância dos gestores públicos, das comunidades epistêmicas e dos especialistas na produção das políticas públicas, os movimentos sociais seriam atores importantes que apresentam "propostas concretas [...] e alternativas a serem apresentadas a governos e que podem ser incorporadas como instrumentos de políticas públicas”. Entendemos que, “a construção das políticas tem uma dimensão relacional, na medida em que seus resultados dependem das interações entre atores políticos e sociais estratégicos, em condições institucionais e conjunturais dadas" (TATAGIBA; ABERS; SILVA, 2018, p. 106).

No rol dessas discussões, é que propomos este artigo a fim de contribuir com os estudos sobre os resultados políticos dos movimentos sociais para as políticas públicas (DOWBOR; CARLOS; ALBUQUERQUE, 2018). Assim, o objetivo deste artigo é compreender os efeitos dos movimentos sociais e das oportunidades políticas para a elaboração do Programa Estadual de Compras Governamentais da Agricultura Familiar e Economia Solidária (Pecafes) no Rio Grande do Norte. Entendemos que as “configurações políticas são, em grande medida, conformadas pela composição dos governos locais, a qual define os atores e interesses que têm (ou não) oportunidades de acesso aos processos de decisão governamental” (SILVA, 2021, p. 1). Portanto, nos atentamos para o momento político em que o Pecafes vai sendo gestado no estado. Esse programa tem como referência os programas nacionais de compra de alimentos da agricultura familiar ${ }^{4}$ fortalecidos e/ou criados nos governos petistas, como o Programa Nacional de Alimentação Escolar (Pnae) e o Programa de Aquisição de Alimentos (PAA). O principal

\footnotetext{
${ }^{4}$ Ressaltamos que, assim como no restante do país, a agricultura familiar do Rio Grande do Norte não é homogênea. Conforme destacam Aquino, Freire e Carvalho (2017, p. 81), "o segmento apresenta uma marcante heterogeneidade socioeconômica que revela padrões produtivos e sociais bastante distintos". Os autores mostram que existe uma predominância de agricultores enquadrados nos grupos A e B do Pronaf, ou seja, são "assentados e produtores pobres ou extremamente pobres. Somados, eles abrangem aproximadamente $80 \%$ do número de estabelecimentos familiares potiguares" (idem). Portanto, as políticas públicas precisam estar atentas a essas diferenciações internas.
} 
objetivo do programa, conforme o art. $1^{\circ}$ da Lei $n^{\circ} 10.536 / 2019$, é "garantir a aquisição direta e indireta de produtos agropecuários, extrativistas e resultantes da atividade pesqueira in natura e beneficiados, produzidos por agricultores e agricultoras”, além de produtos da economia solidária.

Assim como as políticas nacionais, essa política pública estadual visa atender às demandas dos diversos atores que promovem o desenvolvimento rural $^{5}$ do país: o Movimento dos Trabalhadores Rurais Sem Terra (MST), a Confederação dos Trabalhadores na Agricultura (Contag), a Federação dos Trabalhadores na Agricultura no RN (Fetarn), a Federação dos Trabalhadores e Trabalhadoras na Agricultura Familiar do Rio Grande do Norte (Fetraf), além das diversas cooperativas e associações presentes nos territórios. Portanto, buscamos entender como esses atores construíram estratégias, narrativas e repertórios em suas interações com o Estado a fim de garantir a elaboração da política. É importante frisar que o artigo se propôs a discutir os efeitos e consequências das articulações e dos aprendizados desses atores no contexto político, provocando impactos na estrutura de oportunidade política (BOSI; GIUGNI; UBA, 2016). Desse modo, conforme destaca Gupta (2009), os movimentos sociais podem moldar agendas, discursos e normas públicas, mas também se aproveitam de oportunidades políticas, que são entendidas por Tarrow (2009) como dimensões consistentes do ambiente político que podem fornecer incentivos para a ação coletiva ou para a mobilização.

Partimos do pressuposto de que os movimentos sociais aproveitaram a oportunidade política dada pelas eleições de 2018 no RN para introduzir uma demanda sobre a política de compras governamentais na esfera estadual.

A metodologia é essencialmente qualitativa. Utilizamos a gravação de uma audiência pública realizada na Assembleia Legislativa do Rio Grande do Norte (ALRN) intitulada Agricultura familiar e as compras governamentais, ocorrida em 9 de maio de 2019, a fim de compreender os discursos e falas dos movimentos sociais nesse espaço. Também realizamos entrevistas com representantes dos principais movimentos que participaram da mobilização para aprovação do programa: MST, Fetraf - RN, Fetarn, ${ }^{6}$ com gestores governamentais e com a deputada Isolda Dantas (PT), responsável por

\footnotetext{
${ }^{5}$ Compreendemos o desenvolvimento rural a partir da compreensão de liberdade de Amartya Sen (2000). O desenvolvimento, para Sen, implica a expansão das liberdades. Neste sentido, "Sen estabelece um conjunto de aspectos ligados à sua acepção de desenvolvimento, acrescentando ao parâmetro econômico a qualidade de vida e a expansão das liberdades. Considera a liberdade o principal fim, mas também os meios do desenvolvimento" (NARDINI; SOUZA; SACCO DOS ANJOS, 2019, p. 84).

${ }^{6}$ Esses movimentos não só participaram ativamente da discussão da política, mas historicamente têm pautado as demandas da agricultura familiar nas candidaturas estaduais. Portanto, foram peças-chave no entendimento das articulações e de todo o processo.
} 
pautar e propor o programa na ALRN. Como maneira de sistematizar, classificamos as entrevistas no Quadro 1 abaixo.

Quadro 1 - Relação dos entrevistados, cargos ocupados e questões trabalhadas nas entrevistas $^{7}$

\begin{tabular}{|c|c|c|c|}
\hline Entrevistados & $\begin{array}{c}\text { Entidades } \\
\text { que representam }\end{array}$ & Cargos & $\begin{array}{l}\text { Questões } \\
\text { trabalhadas }\end{array}$ \\
\hline $\begin{array}{c}\text { E1 } \\
\text { Isolda Dantas }\end{array}$ & $\begin{array}{c}\text { Assembleia } \\
\text { Legislativa do RN }\end{array}$ & $\begin{array}{c}\text { Deputada } \\
\text { estadual (PT) }\end{array}$ & $\begin{array}{l}\text { Como surge a proposta da política; } \\
\text { envolvimento com a temática; } \\
\text { relação com os movimentos sociais } \\
\text { rurais; desafios para a } \\
\text { aprovação na Assembleia. }\end{array}$ \\
\hline $\begin{array}{c}\mathrm{E} 2 \\
\text { Eduardo/ } \\
\text { ativista institucional }\end{array}$ & $\begin{array}{c}\text { Secretaria de Estado de } \\
\text { Desenvolvimento Rural e } \\
\text { Agricultura Familiar (Sedraf) }\end{array}$ & $\begin{array}{l}\text { Coordenador de } \\
\text { Acesso a Mercados, } \\
\text { Agroindústria e } \\
\text { Cooperativismo }\end{array}$ & $\begin{array}{l}\text { Visão do governo estadual } \\
\text { sobre o programa; relação da Secretaria } \\
\text { com os movimentos sociais; desafios da } \\
\text { implementação da política. }\end{array}$ \\
\hline $\begin{array}{c}\text { E3 } \\
\text { Lucas/ } \\
\text { ativista institucional }\end{array}$ & $\begin{array}{c}\text { Movimentos dos } \\
\text { Trabalhadores Rurais } \\
\text { Sem Terra (MST) e Sedraf }\end{array}$ & $\begin{array}{l}\text { Secretário adjunto } \\
\text { da Sedraf e direção } \\
\text { nacional do MST }\end{array}$ & $\begin{array}{l}\text { Trajetória política; entrada na Sedraf; } \\
\text { os desafios da relação entre } \\
\text { movimentos sociais e Estado; } \\
\text { participação na elaboração do programa; } \\
\text { desafios da implementação. }\end{array}$ \\
\hline $\begin{array}{c}\mathrm{E} 4 \\
\text { Camila/ } \\
\text { militante de } \\
\text { movimentos sociais }\end{array}$ & $\begin{array}{c}\text { Federação dos } \\
\text { Trabalhadores e Trabalhadoras } \\
\text { na Agricultura (Fetraf/RN) }\end{array}$ & $\begin{array}{l}\text { Coordenadora de } \\
\text { Organização da } \\
\text { Produção e } \\
\text { Comercialização }\end{array}$ & $\begin{array}{l}\text { Trajetória política; participação nos } \\
\text { movimentos sociais; participação na } \\
\text { mobilização para a criação do programa; } \\
\text { relação com o Estado; desafios. }\end{array}$ \\
\hline $\begin{array}{l}\text { E5 } \\
\text { Joaquim/ } \\
\text { militante de } \\
\text { movimentos sociais }\end{array}$ & $\begin{array}{l}\text { Federação dos } \\
\text { Trabalhadores Rurais } \\
\text { Agricultores e Agricultoras } \\
\text { Familiares (Fetarn/RN) }\end{array}$ & $\begin{array}{c}\text { Secretário de } \\
\text { Política Agrícola }\end{array}$ & $\begin{array}{l}\text { Trajetória política; participação nos } \\
\text { movimentos sociais; participação na } \\
\text { mobilização para a criação do programa; } \\
\text { relação com o Estado; desafios. }\end{array}$ \\
\hline $\begin{array}{c}\text { E6 } \\
\text { Almir/ } \\
\text { burocrata }\end{array}$ & Sedraf & $\begin{array}{l}\text { Coordenador de } \\
\text { Agroecologia }\end{array}$ & $\begin{array}{l}\text { Trajetória política; visão do governo } \\
\text { estadual sobre o programa; relação da } \\
\text { Secretaria com os movimentos sociais; } \\
\text { desafios da implementação da política. }\end{array}$ \\
\hline
\end{tabular}

Fonte: Elaboração própria, com base na pesquisa realizada pelos autores entre julho de 2019 e dezembro de 2020.

Buscando compreender as estratégias, articulações dos movimentos sociais na relação com as instituições, optamos por trabalhar com as narrativas (POLLETTA, 2006) dos diferentes atores em campo: militantes de movimentos sociais do campo, gestores públicos que atuam na Sedraf (burocrata e ativistas institucionais) e a deputada propositora do Projeto de Lei. Por fim, buscando complementar as narrativas fornecidas pelas entrevistas, utilizamos discursos desses movimentos sociais nos sites das entidades.

\footnotetext{
${ }^{7}$ Em alguns casos, utilizamos nomes fictícios para preservar a identidade dos nossos entrevistados. As entrevistas duraram em média 50 minutos e foram realizadas nos locais de trabalho dos entrevistados antes da pandemia do Covid-19.
} 
Para complementar as informações sobre a política pública, consultamos documentos disponibilizados no site da Sedraf, como a Lei ${ }^{\circ} 10536$ de 3/7/2019, que cria o Programa Estadual de Compras Governamentais da Agricultura Familiar e Economia Solidária (Pecafes) e informações sobre a regulamentação da política.

O artigo segue estruturado em quatro seções, além desta introdução e das considerações finais. A seção um apresenta uma discussão sobre as políticas públicas de compras governamentais, destacando como essas políticas se apresentaram no Rio Grande do Norte. Na segunda seção mostramos como os movimentos sociais aproveitaram a oportunidade aberta por um governo mais sensível às questões sociais e por uma deputada oriunda do meio rural, comprometida com as pautas da agricultura familiar. Na terceira seção tratamos da aprovação do Pecafes, explorando as narrativas empreendidas pelos movimentos sociais a fim de compreender como esses atores percebem a sua influência na formulação da política. Por fim, a seção quatro apresenta alguns dos desafios para a implementação do programa.

\section{As políticas públicas de compras governamentais e as possiblidades das interações socioestatais}

As políticas públicas de compras governamentais, como o PAA, o Pnae e, para o caso do Rio Grande do Norte, o Pecafes, fazem parte do que Grisa e Schneider (2014, p. 125) denominam de terceira geração de políticas públicas para a agricultura familiar e que visam a "construção de mercados orientados pela segurança alimentar e pela sustentabilidade ambiental”. Essas políticas se assentam nas demandas históricas dos movimentos sociais que atuam no campo e acompanham uma "trajetória de políticas públicas que ganharam impulso na década de 1990, por meio da mobilização social e de estudos em desenvolvimento rural, que foram se materializando ao longo dos anos” (KROTH et al., 2019, p. 138). Conforme destacam Rozendo, Bastos e Molina (2013), apesar das compras governamentais de produtos da agricultura não serem recentes no caso do

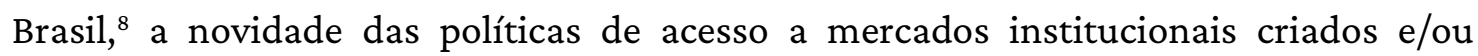
reformulados ao longo dos anos 2000 traz a centralidade do fortalecimento da agricultura familiar, a promoção da segurança alimentar, o resgate de cultivos tradicionais, a redução da pobreza rural e a introdução de estratégias para "induzir o desenvolvimento local a partir da organização da demanda e da participação da agricultura familiar” (GRISA; CALDAS; ÁVILA, 2018, p. 55).

\footnotetext{
${ }^{8}$ Baseados em Grisa e Schmitt (2013), os autores destacam que desde a década de 1930 podemos identificar formas de aquisição de alimentos por parte do Estado, para a formação de estoques, conforme ocorreu com café, por exemplo.
} 
Essas políticas públicas se encontravam no bojo das discussões sobre o Programa Fome Zero, criado em 2003, no início do governo Lula, e buscavam potencializar as áreas rurais do país a partir de estratégias intersetoriais de combate à fome e à pobreza. De acordo com Grisa et al. (2010), podemos dizer que essas políticas surgiram de uma confluência de discussões que estavam acontecendo no país com relação às políticas públicas voltadas para a agricultura familiar nos anos 1990 e que se intensificaram nos anos 2000: de um lado, a discussão sobre a segurança alimentar e nutricional que ganhava fôlego, especialmente com a retomada do Conselho Nacional de Segurança Alimentar e Nutricional (Consea), em 2003 e, de outro, a própria política de crédito para a agricultura familiar, o Programa Nacional de Fortalecimento da Agricultura Familiar (Pronaf), que vinha ganhando outros contornos desde que foi criada, em 1996. Portanto, o surgimento do Programa de Aquisição de Alimentos, em 2003, “integra as demandas de acesso aos alimentos às necessidades de mercado para os produtos da agricultura familiar" (GRISA et al., 2010, p. 139), buscando articular secretarias e ministérios para a sua operacionalização.

O PAA foi criado como uma das ações que compunham a agenda estruturante do Programa Fome Zero. O principal objetivo do PAA refere-se ao fortalecimento da agricultura familiar por meio da compra institucional dos seus produtos pelo Estado a fim de garantir o desenvolvimento do meio rural. De acordo com Sambuichi et al. (2019, p. 13), o PAA tinha como objetivo "criar demanda institucional capaz de estruturar a produção dos agricultores familiares, por meio de garantia de mercado”, além de "garantir o acesso aos alimentos por pessoas que vivem em situação de insegurança alimentar, repassando para a rede de equipamentos públicos de alimentação e nutrição, para instituições assistenciais, escolas e destinando à formação de estoques públicos ou outras finalidades" (CARVALHO; BEKER; NESKI, 2019, p. 25419). O PAA, assim como outras políticas criadas nos governos Lula e Dilma, não busca apenas entregar um produto ou serviço para a população, "mas alia esse processo ao fortalecimento dos grupos ou de ações coletivas” (PISMEL, 2017, p. 5).

O PAA é executado em seis modalidades: Compra com Doação Simultânea, Compra Direta, Apoio à Formação de Estoques, Incentivo à Produção e ao Consumo de Leite, ${ }^{9}$ Compra Institucional e Aquisição de Sementes.

No Rio Grande do Norte, o PAA começou a ser implementado em 2003, mas poucos municípios conseguiram aderir ao Programa visto que muitos agricultores familiares não possuíam a Declaração de Aptidão (DAP), documento básico para o acesso às

\footnotetext{
${ }^{9}$ Vale notar que no estado já existia uma política de compra governamental do leite, instituída pela primeira vez em 1986. Entretanto não havia nenhum tipo de obrigatoriedade de compra de leite da agricultura familiar.
} 
políticas para agricultura familiar. Além disso, verificou-se a falta de produção suficiente para a venda, assim como dificuldades para transportar e armazenar os produtos (ROZENDO, 2017).

Atualmente, o PAA continua sendo executado no estado, mesmo com os cortes governamentais impostos pela atual conjuntura. Segundo dados da Conab (2020), em 2019 foram gastos R\$1.447.82,00 no RN, sendo os recursos distribuídos da seguinte maneira: Aquisição de Sementes: R \$ 595.035,00; Compra com Doação Simultânea: R\$ 788.851,00; e Apoio à Formação de Estoques: R\$ 63.916,00, ficando em quarto lugar entre os estados do Nordeste com mais projetos executados. Entretanto, nota-se uma perda significativa se comparado à execução do PAA nos governos Lula e Dilma. Em 2011, por exemplo, foram aportados pelo RN o valor de $\mathrm{R} \$ 18.389 .982,00$, muito acima dos valores atuais.

Assim como o PAA, seguindo a dinâmica das compras institucionais, o Pnae visa fortalecer a agricultura familiar do país. Criado nos anos 1950, como uma política para a merenda escolar, o Pnae é reconhecido mundialmente como a política pública para a alimentação escolar de maior longevidade. Apesar das diversas modificações que foram acontecendo no programa desde a sua criação, destacamos duas principais que buscam formalizar as relações entre sociedade e Estado e fortalecer as organizações da agricultura familiar: a primeira, refere-se à obrigatoriedade de criação dos Conselhos de Alimentação Escolar (CAEs) pelos municípios para que tenham acesso ao repasse de verbas pelo governo federal, em 2000; a segunda alteração refere-se à obrigatoriedade de compra de, no mínimo, $30 \%$ de produtos da agricultura familiar para a alimentação escolar, em 2009.

Nota-se que entre 2010 e 2012 houve um aumento significativo no "número de Entidades Executoras que compraram produtos da agricultura familiar para atender as necessidades nutricionais dos alunos, saindo de 48\% em 2010 para 67\% em 2012" (DIAS; OLIVEIRA, 2019, p. 5). Ainda conforme os autores, o estado do RN acompanhou esse crescimento nesse período, inclusive superou em "2012 a média nacional de $29 \%$ e a regional de 23\%” (DIAS; OLIVEIRA, 2019, p. 8).

Entretanto, assim como o PAA, essa política também sofreu cortes orçamentários que tiveram consequências negativas para a agricultura familiar, bem como para a segurança alimentar e nutricional dos alunos da rede pública de ensino no país todo. Mas, ainda que essas políticas estejam sendo desestruturadas desde 2016 (MATTEI, 2016), elas possibilitaram um acúmulo social e político tanto para os movimentos rurais no RN, que participaram da política, como para ativistas que assumiram cargos na gestão estadual e para a própria Isolda Dantas, propositora do Projeto de Lei na 
Assembleia. Esta última trabalhou entre 2010 e 2014 no Ministério do Desenvolvimento Agrário (MDA) na execução de políticas públicas para mulheres rurais.

Essas experiências em gestões petistas também podem ser consideradas um ponto importante de aprendizado que foi aproveitado para sinalizar a importância do diálogo com a sociedade civil na elaboração de propostas, conforme destacaremos mais à frente.

\section{Os movimentos sociais e a janela de oportunidade}

A atuação dos movimentos sociais no RN já data de um longo período, que remonta por volta dos anos 1960, com a participação das Comunidades Eclesiais de Base (CEBs). Daquele momento até os dias atuais foram diversas as atuações, desde a participação nos conflitos fundiários e pelos pedidos de regularização de posse das terras, até as pressões por políticas públicas específicas para a agricultura familiar, inclusive relacionadas à problemática da comercialização. Essa dinâmica foi perpassada por confrontos entre movimentos sociais e Estado. Entretanto, a partir dos anos 1990, mais especificamente com a criação do Programa Nacional de Fortalecimento da Agricultura Familiar (Pronaf), em 1996, as articulações entre movimentos sociais rurais e Estado começaram a se tornar possíveis, especialmente no âmbito local, após a instituição dos Conselhos Municipais de Desenvolvimento Rural Sustentável (CMDRs). Essa articulação entre Estado e sociedade civil se fortaleceu ainda mais com o estabelecimento de políticas de desenvolvimento rural com viés territorial, como o Programa Nacional de Desenvolvimento Sustentável de Territórios Rurais (Pronat), criado em 2003, no início do primeiro mandato do governo Lula. Por meio dele buscou-se estimular e promover o protagonismo dos atores sociais para a construção da governança do desenvolvimento de seus territórios. Essa estratégia governamental voltada ao desenvolvimen to com enfoque territorial, iniciada com o Pronat, foi reafirmada em 2008, com o lançamento do Programa Territórios da Cidadania (PTC), no segundo mandato de Lula. Assim, a discussão sobre desenvolvimento territorial congregou a diversidade de organizações e instituições no meio rural em constante diálogo com o Estado a partir da instituição dos Colegiados ou Fóruns Territoriais. No RN, esses espaços foram bastante propositivos no que se refere às demandas por políticas para a agricultura familiar, especialmente pautando a criação de uma Central de Comercialização de Produtos da 
Agricultura Familiar e Economia Solidária (Cecafes), ${ }^{10}$ conforme destaca a representante da Fetraf:

A política territorial foi fundamental para unir esses atores, para que pudesse fortalecer e ter a estrutura que temos hoje. Não é só uma região é o estado todo, todos os territórios. E aí, com isso, a Cecafes foi executada, a estrutura, aí vamos a luta para fazer acontecer, né? (...) e chegamos na Cecafes, comercializando na Cecafes, tudo organizadinho, com DAP e tal. Mas a Cecafes é uma vitrine, (...) é uma política nova ainda, de divulgação ainda. A gente já conhece o Pnae, a gente sabe que tem dinheiro no Pnae, né? (E4, informação verbal)

Percebendo a oportunidade que surgiu no contexto político do Rio Grande do Norte, durante a eleição de 2018, esses movimentos (MST, Fetraf, Fetarn) encabeçaram um apoio massivo às candidaturas de Fátima e demais candidatos(as) petistas à Assembleia Legislativa, conforme destaca o atual secretário adjunto da Sedraf e militante do MST:

No último período, o MST participou ativamente da questão eleitoral do RN, que era um momento decisivo para nós eleger a professora Fátima [...] Natália [Bonavides] para deputada federal e Isolda para estadual. [...] Foi a primeira vez que o movimento se empenhou tanto numa campanha eleitoral porque ganhou traços de lutas de classes. Não tinha jeito, tinha que se envolver mesmo. (E3, informação verbal)

Logo no início da gestão, a governadora Fátima Bezerra realizou uma reforma administrativa no desenho institucional do Estado. Tal reforma contou com a alteração da antiga Secretaria de Estado de Assuntos Fundiários e de Apoio à Reforma Agrária (Seara) para a nova Secretaria de Estado de Desenvolvimento Rural e da Agricultura Familiar (Sedraf). A inclusão do termo "agricultura familiar" no nome da pasta possui uma natureza simbólica que nos permite perceber que a pauta da agricultura familiar passa a ganhar maior relevância no âmbito estadual, inclusive expressando a necessidade de pautar políticas que buscassem estimular o desenvolvimento rural no estado. O coordenador de Agroecologia da Sedraf explica essa mudança:

A primeira é assim, a Seara tinha o foco basicamente na questão da regularização fundiária e crédito. E aí, a Sedraf chega com essa perspectiva de ampliar e trabalhar fortemente a questão da agricultura familiar. Acho que aí já tem um aspecto relevante que é a ampliação, que é olhar para um setor muito específico do nosso estado que é muito grande, apesar de não ter visibilidade. (E8, informação verbal)

\footnotetext{
${ }^{10}$ As instalações da Cecafes foram criadas em 2007, mas somente em 2017, no período do governo de Robinson Faria (Partido Social Democrata - PSD), começou realmente a funcionar "após inúmeras controvérsias com o governo estadual" (ALMEIDA et al., 2020, p. 505). O Partido dos Trabalhadores, nesse período, fazia parte da coalizão governista, entretanto, o partido rompe com o governo após o deputado federal Fábio Faria, do mesmo partido do governador Robinson Faria, anunciar publicamente que votaria a favor do impeachment da Presidenta Dilma Rousseff (PT), em 2016.
} 
Para Silva Júnior, Nascimento e Moura (2020), houve a inserção de militantes no âmbito da gestão pública e isso possibilitou uma ampliação na construção de estratégias para implementar políticas públicas pautadas pelos movimentos sociais. Nesse sentido, os valores e ideias dos movimentos sociais passaram a afluir diretamente na agenda governamental através dos ativistas institucionais da atual gestão.

Com uma sinalização positiva do executivo estadual, da eleição de candidaturas ligadas ao tema da agricultura familiar e com a recém-criação da Sedraf, é possível inferir que a articulação de militantes com atores da burocracia, a fim de propor institucionalmente um programa que viesse a somar no desenvolvimento da agricultura local, passou a se tornar pauta prioritária na agenda desses movimentos sociais. Como afirmam Tatagiba, Abers e Silva (2018, p. 112), “os movimentos não só aproveitam as oportunidades colocadas pela conjuntura, como, no caso da presença de aliados em posições de poder”.

Assim, a proposição de um programa de compras governamentais no início do mandato da deputada Isolda Dantas tem relações diretas com o contexto histórico de lutas dos agricultores familiares no estado, mas também com a própria trajetória militante de Isolda Dantas nas articulações com as mulheres rurais do Rio Grande do Norte. A fala a seguir mostra o envolvimento da deputada com os movimentos rurais:

Isolda é uma deputada que vem lapidada com todos os desejos da agricultura familiar. Eu a conhecia da luta [...] ela veio de dentro dos movimentos. Havia um discurso bem afinado que não é de agora. Ela unifica a luta; (E2, informação verbal)

Neste sentido, a proximidade da deputada e da governadora com os movimentos sociais do campo foi essencial para a entrada da temática na agenda. A aceitação governamental do Pecafes está relacionada, assim, à eleição de Fátima Bezerra e de Isolda Dantas, à presença ativa dos movimentos nas lutas pela agricultura familiar e aos aprendizados institucionais. Esses fatores foram essenciais para a elaboração e aprovação da lei que cria o Pecafes.

\section{A aprovação do Pecafes e os diálogos participativos}

A Lei $\mathrm{n}^{\circ}$ 10.536, de 3 de julho de 2019, “cria o Programa Estadual de Compras Governamentais da Agricultura Familiar e Economia Solidária (Pecafes) no Estado do Rio Grande do Norte e dá outras providências”. De acordo com o Art. $1^{\circ}$ :

O Pecafes [...] tem a finalidade de garantir a aquisição direta e indireta de produtos agropecuários, extrativistas e resultantes da atividade 
pesqueira, in natura e beneficiados produzidos por agricultores e agricultoras ou suas organizações socioeconômicas rurais, por povos e comunidades tradicionais e pelos beneficiários e beneficiárias da agricultura familiar como forma de assegurar o desenvolvimento rural sustentável, a promoção da segurança e soberania alimentar e nutricional e o incrementos à geração de trabalho e renda.

Uma série de espaços de debate e escuta deu início à maturação da formulação do programa, em que o mandato da deputada Isolda Dantas, em parceria com os movimentos sociais, discutiu acerca das possíveis possibilidades e entraves do programa. Para além disso, a deputada articulou as secretarias de Agricultura dos municípios e a recém-criada Secretaria Estadual (Sedraf). "A deputada Isolda teve a iniciativa de encabeçar esse processo e inclusive com a parceria da recém criada Sedraf [...] passamos a contribuir com esse processo no sentido de formulação da lei” (E3, informação verbal).

O representante da Fetarn também ressalta a participação ampla de setores da sociedade civil na discussão sobre a política nos territórios do estado, incluindo atores como as cooperativas da agricultura familiar, os sindicatos rurais, os movimentos sociais que compõem a Articulação do Semiárido (ASA) e acadêmicos e pesquisadores da temática.

Desse modo, percebemos que, apesar da pluralidade de entidades participantes, alguns atores tiveram maior centralidade na definição da política, dentre eles destacamse a Fetarn, a Fetraf - RN e o MST, conforme a fala abaixo:

\begin{abstract}
esses são os que mais dialogam com a Secretaria, com esse campo do governo mesmo. Quem dialoga de forma mais organizada, que chega e pauta, bota fora, propondo coisas. Os outros até chegam, com pautas mais pontuais e tal. Chegam, a gente dialoga com eles, mas esses são aqueles que realmente dão mais para a política, [...] esses três movimentos são os principais que fazem isso. (E2, informação verbal)
\end{abstract}

A narrativa utilizada pelos atores sobre a importância do projeto para a sociedade ressalta a participação popular na condução do processo e como estratégia utilizada para conquistar a sensibilidade dos demais deputados presentes na Assembleia. Segundo Isolda Dantas, essa foi umas das estratégias empregadas para garantir a aprovação do PL. "O projeto precisa ter um apelo social, precisa ter a sociedade para se justificar e ele não morrer. Porque pode ter um projeto e eles [deputados] falam assim: legal, mas não teve a sociedade mobilizada?”. Ou seja, na fala da deputada, fica evidente a preocupação com o apoio popular que alguns projetos deveriam ter, inclusive ressaltando que se não há apoio popular pode enfraquecer a articulação para a votação na Assembleia. 
Todos os entrevistados representantes dos movimentos ressaltaram que o fato de o programa ser uma demanda antiga dos movimentos que atuam no campo e ter sido construído com a participação da sociedade, fez com que nenhum deputado votasse contrário à sua aprovação. De acordo com a representante da Fetraf, a articulação entre os movimentos e os discursos reproduzidos nos espaços de discussão foram fundamentais para que os deputados aprovassem o projeto. Segundo ela:

Em toda movimentação que acontecia do Pecafes, as federações e sindicatos se articulavam para ir à Assembleia para sensibilizar. E os deputados: “opa, peraí, aqui tem um muro maior”. Então isso foi fundamental, essa união dos agricultores. E a gente estava muito afinado no discurso, porque não é de agora né? (E4, informação verbal)

Nesse ínterim, a deputada propôs a audiência pública intitulada A agricultura familiar $e$ as compras governamentais no $R N$, que aconteceu no dia 9 de maio de 2019 e contou com a presença de políticos, militantes, acadêmicos e demais representantes da sociedade civil. O objetivo da audiência, segundo a deputada Isolda Dantas, era:

para que a gente possa de forma institucional receber as contribuições para o projeto Lei [...] um projeto Lei que nós apresentamos no nosso mandato, mas fruto de processos anteriores construídos pelos movimentos de agricultura familiar. (Fala da deputada Isolda durante a audiência pública)

Trata-se de mostrar de maneira explícita que havia uma participação anterior que envolveu diversas discussões sobre o projeto em diferentes espaços do estado, seja nos colegiados territoriais, ${ }^{11}$ seja nas reuniões com as cooperativas da agricultura familiar e com os sindicatos rurais e que estaria se consolidando no PL.

Para o atual secretário da Sedraf, o momento da audiência pública é simbólico, pois "nós não temos a dimensão desse programa para a agricultura familiar do RN. Ainda mais pelo momento em que estamos vivendo. Ontem tivemos a aprovação da Sedraf, outro pleito histórico [...] as coisas começam a acontecer” (fala do secretário na audiência pública).

Com relação à questão de gênero, a representante da Marcha Mundial das Mulheres (MMM), Francisca Eliene da Silva, conhecida como Neneide, aponta que o programa vem contribuir para o reconhecimento das mulheres rurais em dinâmicas autoorganizativas e na superação da violência. "Para nós, o Pecafes é muito importante, pois é um sonho de nós produtoras que nos organizamos, [...] é a partir dessa auto-

\footnotetext{
${ }^{11}$ Os colegiados territoriais foram criados a partir dos anos 2000, como espaços de articulação das políticas territoriais. "O Colegiado Territorial (também denominado Fórum ou Conselho) é uma institucionalidade que reúne representantes do poder público e da sociedade civil atuantes no território, com o objetivo de ampliar a participação social, a representação das organizações que compõem o território e a articulação necessária para a gestão social das políticas públicas” (MOURA; MOREIRA; GOMES, 2017, p. 77).
} 
organização que a gente consegue romper com a violência” (fala de Neneide na audiência, maio de 2019). Ela aponta ainda que o aspecto econômico tem relação direta com essa violência, e que através da venda de produtos das agricultoras familiares há a possibilidade de enfrentar essa situação tão presente na vida delas.

O programa também insere as demandas da economia solidária com diferentes produções não apenas no meio rural, mas também nos espaços urbanos, especialmente nas periferias das grandes cidades. Portanto, para Neneide, é essencial pensar esse programa como uma bandeira de luta das mulheres nos diferentes espaços. As variadas formas de produção das mulheres dentro da economia solidária, como o artesanato, material de limpeza, entre outros, mostram como o Estado pode se apropriar desses produtos na gestão. Segundo Neneide: “Tem várias mulheres na cidade e no campo que são costureiras [...] e que podem formar equipe para produzir os uniformes dos hospitais [...] a economia solidária não está só no campo" (fala de Neneide na audiência, maio de 2019).

Dowbor, Carlos e Albuquerque (2018) afirmam que a confluência da inovação social e da alternativa pode resultar num instrumento de política pública, entendido aqui como o dispositivo legal, ou seja, o meio de execução da inovação social anteriormente criada. $\mathrm{O}$ acúmulo de debates e proposições do Pecafes resultou, por fim, na Lei Estadual $\mathrm{n}^{\circ} 10.536 / 2019$ aprovada por unanimidade na Assembleia Legislativa e sancionada pela governadora do estado, em 3 de julho de 2019.

Essa luta começou há muito tempo, da agricultura familiar pela
sobrevivência e pela qualidade de vida e permanência do homem e da
mulher no campo. Para estarmos aqui hoje fizemos muitos diálogos com
a Sedraf, agricultores, movimentos. Foi um projeto feito a muitas mãos”.
(Fala da deputada Isolda durante cerimônia de sanção da lei)

As discussões sobre o projeto foram feitas em vários momentos, mas ressalta-se que houve reuniões separadas entre a deputada e representantes do seu mandato e os diversos movimentos sociais que atuam no meio rural. Isso deve-se ao fato de haver algumas divergências sobre o formato da política, mostrando que a prática da participação também pode gerar conflitos. Na fala de Isolda Dantas, isso fica claro:

Foi preciso dialogar separadamente com os movimentos. [...] A gente foi incorporando o que cada um foi dizendo de forma separada [...]. A audiência pública foi então o momento de consolidação das partes separadas num ato de pensar o projeto de maneira coletiva. (E1, informação verbal)

A audiência foi bastante movimentada com a presença ativa das representações dos movimentos rurais. Pelo fato de haver muita militância de esquerda nesse espaço, um deputado, que mesmo não votando contra o PL, tentou causar um desconforto no dia, 
conforme relatado pelo coordenador de Acesso a Mercados, Agroindústria e Cooperativismo da Sedraf:

para provocar quem estava na plateia, que era tudo de esquerda [um deputado] ficou lá com esse tal do vídeo [de produção da direita] e o povo vaiando, o povo reclamando e ele colocou para atiçar o povo contra ele, e ele votou a favor, mas ele ficou o tempo todo na sessão provocando. Provocou a Isolda umas três vezes por causa de uns três pontos que estavam sendo votados [...] foi tão engraçado [...] que ele queria xingar ela por alguma coisa, mas não sabia o que falar porque estava no meio da Assembleia e ele olhou assim para ela: "Você é uma Maria do Rosário" (risos), ela ria e fazia: "Você está me xingando é?". Então é um clima pesado, né, mas nem ele votou contra, entendeu? (E2, informação verbal)

A citação anterior destaca que o deputado, no dia da votação, não se opôs ao projeto, pois havia uma pressão popular muito grande constatada em outros espaços participativos. Percebemos que na época de proposição e votação do Pecafes, mesmo podendo existir divergências acerca do conteúdo da política impulsionadas pelas vivências e posicionamentos políticos dos deputados, o Pecafes não encontrou dificuldades na sua aprovação na Assembleia Legislativa do RN, tendo em vista que ela foi unânime. A antiga reivindicação de uma política estadual de compras governamentais, somada ao apoio do governo estadual, pode ter diluído os conflitos legislativos para a aprovação do programa. A aprovação unânime do Pecafes reflete a sólida base na qual o programa foi construído: apoio governamental, apoio da sociedade civil e acúmulo de experiências anteriores.

De acordo com Dowbor, Carlos e Albuquerque (2018), um instrumento de política pública pode se originar de arranjos e instrumentos já existentes. Nesse sentido, a influência do PAA e Pnae (instrumentos preexistentes) representa também uma significativa contribuição para o surgimento do Pecafes como novo instrumento de política pública.

\section{Próximos passos: a regulamentação e a disputa de interesses}

No momento da pesquisa, o Pecafes estava passando pela discussão na Sedraf sobre sua regulamentação. Segundo Isolda Dantas, durante a audiência pública, "o processo de regulamentação é tão importante quanto a elaboração da lei” (informação verbal). A regulamentação da política pública impõe uma série de novos desafios a serem enfrentados pelos atores envolvidos:

Hoje nós estamos contribuindo com o processo de regulamentação do Pecafes e para nós é uma das principais leis que foram criadas no governo Fátima. [...] Mas não adianta só ter a lei, muitas vezes as associações e cooperativas não conseguem fornecer porque não tem estrutura mínima 
[...] está sendo discutida uma lei que vai beneficiar as cooperativas e também discutimos um crédito específico para capital de giro. (E3, informação verbal)

Apesar de desafiador, os propositores da política compreendem que é realmente possível a implementação do Pecafes, dada a circunstância política do RN, através da sinalização positiva do governo estadual, dos arranjos institucionais que estão em trânsito na ALRN, como a Frente Parlamentar da Pesca e Aquicultura, o endosso do presidente da comissão, o deputado Souza (PHS), do deputado Francisco do PT (PT) e dos demais parlamentares, além das relações e redes criadas a partir da inserção de militantes no Estado, denominados de ativistas institucionais.

Para a regulamentação da lei, tem-se vislumbrado a possibilidade de conhecer projetos similares para compreender os desafios e alguns resultados. O diretor de produção da Sedraf comenta que uma das preocupações da Secretaria nesse momento, para além da regulamentação, é entender a dinâmica de implementação da política em outros estados, como no Ceará, por exemplo:

tem toda uma série de etapas que ele [secretário da Sedraf] está matutando na cabeça, queimando os neurônios como é que faz porque é muito novo. Quem já fez isso, meu Deus? Eu estava querendo ir para o Ceará porque no Ceará eles aderiram, já faz um tempo, aprovaram a lei e eles estão tentando implementar de fato e regulamentaram novamente no final do ano e tal, e aí parece que está andando e a gente quer ir lá ver como está. (E2, informação verbal)

Para acessar o Pecafes, as chamadas “instituições da agricultura familiar”, que são as cooperativas, os agricultores, as associações, entre outros, deverão se cadastrar em portal eletrônico criado pelo governo do estado em parceria e apoio tecnológico da Universidade Federal do Rio Grande do Norte (UFRN). A fiscalização será feita por intermédio da Emater, tanto para as compras diretas (governo) quanto para as indiretas (empresas que necessitam de licitação para a compra de alimentos para presídios, restaurantes populares etc.), fiscalizando, assim, o crédito, o cumprimento de prazos de pagamentos do governo, dentre outras ações. Serão necessárias ainda, para as licitações, nota fiscal e certificação. Tais arranjos demandam dos gestores e demais atores envolvidos na política, o entendimento da burocracia a qual estão sujeitos os projetos e as leis aprovadas.

O fato de o programa modificar a lógica de compra de produtos alimentícios no estado poderá resultar em embates ainda não mensuráveis pelos atores que participaram da elaboração da política. Mas a reação pode ser imaginada a partir de outras experiências de proteção ao agricultor familiar (MOLINA et al., 2014). Segundo o diretor de produção da Sedraf, há ainda passos importantes a serem dados para garantir 
que a lei saia do papel. Esse processo poderá contar com a articulação de interesses de grandes produtores e dos grandes atacadistas do comércio que sempre venderam seus produtos e que agora terão que disputar espaço com a agricultura familiar.

A gente estava até falando que vai mexer em muito interesse e tal. Essa semana teve uma pessoa de uma entidade que presta serviço para um fornecedor do estado e já veio aqui saber como é essa lei, já sentiu que tem um clima [...] eles estão preocupados, estão com medo porque vai tirar o mercado deles e quando eles souberem, por exemplo, que nossa meta é tirar toda compra direta pelo menos, que não é só trinta por cento? Eles vão ficar loucos com isso, entendeu? (E2, informação verbal)

Essa articulação multinível, representada pelas relações entre atores governamentais e não governamentais em âmbito local representa uma série de possibilidades analíticas para o futuro do Pecafes. Para Reis (2019), a governança multinível está relacionada com a complexidade dos processos que envolvem tomadas de decisão e que elucidam os desdobramentos da ação coletiva, impulsionando o desenvolvimento regional. No nosso caso, a interação entre burocratas e movimentos sociais no processo de elaboração do Pecafes abre portas para um processo contínuo de controle social por parte da sociedade civil por meio dos movimentos rurais no acompanhamento da implementação e execução do Programa.

De acordo com Henrichs e Meza (2017), a complexidade das relações socioestatais nos impõe a necessidade de analisar essas relações a partir de uma perspectiva de compreensão na esfera local e regional. Para as autoras, a articulação mutinível possibilita uma melhoria nas relações intergovernamentais e impulsiona o desenvolvimento regional a partir da inserção democrática de atores nos diversos processos de planejamento, implementação, gestão e acompanhamento de políticas públicas.

Ao mesmo tempo que se propõe a dar protagonismo aos agricultores familiares do estado, o Pecafes poderá enfrentar alguns desafios pela frente. A falta de diálogo entre a Sedraf e a Secretaria de Estado da Agricultura, da Pecuária e da Pesca (Sape) na elaboração e formulação do Programa sinaliza desafios para a Secretaria de Agricultura Familiar, que, com menor estrutura, pode encontrar limitações no processo de implementação de um programa complexo nos moldes do Pecafes.

Destaca-se o fato de que, mediante pesquisa empírica e documental, percebemos que a Sape, apesar de possuir uma Subcoordenadoria de Agricultura Familiar, não possui relação ou proximidade direta com o Programa nos estágios iniciais de sua formulação e consolidação como lei, uma vez que as ações centrais da Sape são voltadas ao agronegócio, conforme destaca o entrevistado E6: 
São Secretarias que, mesmo trabalhando na mesma perspectiva da agricultura, uma é agricultura familiar [Sedraf], a outra muito na perspectiva do agronegócio, a Sape. É uma relação de parceria quando tem demandas da Sedraf que precisam ser resolvidas com a Sape. A gente consegue resolver com tranquilidade, mas cada uma no seu canto, né? (E6, informação verbal; grifo nosso)

Nesse sentido, para além das capacidades administrativas, será necessária a efetivação das capacidades políticas por parte dos burocratas da Sedraf no processo de consolidação do Programa. Portanto, o governo deverá se articular com os diferentes grupos e movimentos sociais, além de secretarias e órgãos governamentais, a fim de mostrar a viabilidade da política e gerar esclarecimentos sobre sua necessidade. Esse é o grande desafio para os próximos anos.

\section{Considerações finais}

A partir de experiências anteriores como o PAA e o Pnae, e do envolvimento de diversos atores (burocratas, movimentos sociais, pequenos produtores, entre outros) nessas políticas, observou-se um aprendizado institucional (GRISA; SCHNEIDER, 2014) que contribuiu para a formulação e execução de políticas de acesso aos mercados institucionais. Entendemos que esse acúmulo, portanto, foi fundamental para o surgimento do Pecafes no Rio Grande do Norte.

A respeito do Programa Estadual de Compras Governamentais da Agricultura Familiar e Economia Solidária (Pecafes), percebemos que as articulações de entidades da sociedade civil, em constante relação com a deputada Isolda Dantas, do PT, confluíram para a sua aprovação unânime na Assembleia Legislativa do Rio Grande do Norte, em 11 de junho de 2019, após quatro meses tramitando. Ou seja, entendemos que "a construção das políticas tem uma dimensão relacional, na medida em que seus resultados dependem das interações entre atores políticos e sociais estratégicos, em condições institucionais e conjunturais dadas” (TATAGIBA; ABERS; SILVA, 2018, p. 106).

Esse Programa tem como referência os programas nacionais de compra de alimentos da agricultura familiar fortalecidos e/ou criados nos governos petistas, como o Programa Nacional de Alimentação Escolar (Pnae) e o Programa de Aquisição de Alimentos (PAA). O principal objetivo do Pecafes é "garantir a aquisição direta e indireta de produtos agropecuários, extrativistas e resultantes da atividade pesqueira in natura e beneficiados, produzidos por agricultores e agricultoras”, além de produtos da economia solidária.

Assim como as políticas nacionais, essa política pública estadual vem atender as demandas dos diversos atores que promovem o desenvolvimento rural do país. A 
articulação entre o Movimento dos Trabalhadores Rurais Sem Terra (MST), a Confederação dos Trabalhadores na Agricultura (Contag), a Federação dos Trabalhadores na Agricultura no RN (Fetarn), a Federação dos Trabalhadores e Trabalhadoras na Agricultura Familiar do Rio Grande do Norte (Fetraf), as diversas cooperativas e associações presentes nos territórios e demais entidades, em parceria com a nova Secretaria Estadual de Desenvolvimento Rural e Agricultura Familiar (Sedraf), possibilitou a criação do Programa. A aprovação do Pecafes aparece como um dos exemplos de articulações entre Estado e movimentos para inserção de demandas históricas da agricultura familiar na agenda governamental.

$\mathrm{Na}$ parte analítica, realçamos que o programa era uma demanda antiga dos movimentos representantes dos pequenos produtores rurais e a sua construção se deu com a participação da sociedade aproveitando a oportunidade política dada diante das eleições de 2018. Mostramos também as narrativas utilizadas pelos atores nas audiências públicas realizadas, que foram essenciais para a sensibilização de apoiadores no Legislativo e entre grupos da sociedade.

Nesse sentido, ao analisarmos o caso do programa à luz dos conceitos de Dowbor, Carlos e Albuquerque (2018), podemos afirmar que o Pecafes se iniciou como uma inovação social, impulsionada pelos movimentos sociais do campo, ao trazer para o centro do debate uma experiência inovadora de compras governamentais no âmbito estadual, em seguida, após intenso diálogo entre movimentos sociais e legislativo, transformou-se em alternativa ao virar projeto de lei na Assembleia Legislativa e, por fim, ganhou status de instrumento de política pública por meio da aprovação no plenário.

O empenho dos atores envolvidos na aprovação do Pecafes - desde a mobilização dos militantes pela agricultura familiar e economia solidária até a aceitação por parte da governadora, passando pela proposição da deputada Isolda Dantas - e o contexto de oportunidade política, iniciado com a eleição de Fátima Bezerra e Isolda Dantas, fortalecido com a criação da Sedraf e a inserção de militantes na gestão do executivo estadual, concretizada pela aceitação governamental da proposta do programa, foram fundamentais para a consolidação da agricultura familiar no campo político do RN.

A proposição, por parte de movimentos sociais, de alternativas perante as demandas sociais se constitui um campo analítico crescente no Brasil. Nesse sentido, através do caso do Pecafes, fica clara a capacidade organizava e propositiva dos movimentos sociais ao explorarem vias alternativas para além das mobilizações contestatórias frequentemente utilizadas. Essa capacidade organizativa pode ser entendida como um 
dos resultados de experiências anteriores como as políticas federais de compras governamentais, como o PAA e Pnae.

Assim, entendemos que a luta dos movimentos sociais da agricultura familiar e economia solidária no Rio Grande do Norte teve êxito num primeiro momento, mas que ainda é preciso haver articulação entre os movimentos sociais e o Estado a fim de garantir a implementação e a execução do Pecafes, conforme pensado e originalmente defendido.

\section{Agradecimentos}

Uma primeira versão deste artigo foi apresentada no $12^{\circ}$ Congresso da Associação Brasileira de Ciência Política (ABCP), em 2020, com comentários de Eduardo Marques (USP), a quem os autores agradecem imensamente pelas contribuições. Também agradecemos a leitura atenta e os comentários de membros do Grupo de Pesquisa Estado e Políticas Públicas, da Universidade Federal do Rio Grande do Norte (UFRN), nas pessoas de Alan Lacerda, Alexsandro Cardoso, Lindijane Almeida e Sandra Gomes.

\section{Referências}

ALMEIDA, Letícia de Souza; SANTOS, Carine de Jesus; ROZENDO, Cimone; PENHA, Thales Augusto Medeiros; ARAÚJO, Joaquim Pinheiro de. O papel das cadeias curtas de comercialização na construção de um modelo de desenvolvimento rural sustentável no semiárido nordestino: o caso da Central de Comercialização da Agricultura Familiar do Rio Grande do Norte (CECAFES). Desenvolvimento e Meio Ambiente, Curitiba, v. 55, p. 494-516, 2020. Disponível em: https://revistas.ufpr.br/made/article/view/74160. Acesso em: 4 jun. 2021.

ABERS, Rebecca; SERAFIM, Lizandra; TATAGIBA, Luciana. Repertórios de interação Estadosociedade em um Estado heterogêneo: a experiência na era Lula. Dados, Rio de Janeiro, v. 57, n. 2, p. 325-357, 2014. Disponível em: http://dx.doi.org/10.1590/0011-5258201411. Acesso em: 2 mar. 2021.

ALMEIDA, Carla; TATAGIBA, Luciana. Os conselhos gestores sob o crivo da política: balanços e perspectivas. Servico Social e Sociedade, São Paulo, n. 109, p. 68-92, 2012.

AQUINO, Joacir Rufino de; FREIRE, José Aldemir; CARVALHO, Augusto Carlos de. Importância, heterogeneidade e pobreza da agricultura familiar no estado do Rio Grande do Norte. Geotemas, Pau dos Ferros, v. 7, n. 2, p. 66-92, 2017. Disponível em: http://natal.uern.br/periodicos/index.php/GEOTemas/article/view/813. Acesso em: $21 \mathrm{fev}$. 2021.

BOSI, Lorenzo; GIUGNI, Marco; UBA, Katrin. The consequences of social movements. Cambridge: Cambridge University Press, 2016.

CARVALHO, Paulo Roberto; BECKER, Cláudio; NESKE, Marcio Zamboni. Avanços e recuos na 
Execução do programa de aquisição de alimentos (PAA): comparando as experiências de Lajeado/RS e Santana do Livramento/RS. Brazilian Journal of Development, v. 5, n. 11, p. 25415 25437, 2019. Disponível em:

https://www.brazilianjournals.com/index.php/BRJD/article/view/4691. Acesso em: 15 fev. 2021.

CONAB - Companhia Nacional de Abastecimento. Agricultura familiar - Programa de Aquisição de Alimentos - PAA: resultados das ações da Conab em 2019. Compêndio de Estudos CONAB, Brasília, v. 27, 2020. Disponivel em https://www.conab.gov.br/agricultura-

familiar/execucao-do-paa/compendio-execucao-do-paa/item/14475-compendio-paa-2019. Acesso em: 8 mar. 2021.

DIAS, Thiago Ferreira; OLIVEIRA, Erysson Faustino. Agricultura familiar, políticas públicas e mercados institucionais: uma análise exploratória do Programa Nacional de Alimentação Escolas - PNAE no Rio Grande do Norte. Holos, Natal, v. 5, p. 1-19, 2019. Disponível em: https://www2.ifrn.edu.br/ojs/index.php/HOLOS/article/view/6838. Acesso em: 9 fev. 2021.

DOWBOR, Monica; CARLOS, Euzeneia; ALBUQUERQUE, Maria do Carmo. As origens movimentalistas de políticas públicas: proposta analítica aplicada às áreas de criança e adolescente, direitos humanos e saúde. Lua Nova, São Paulo, v. 105, p. 47-80, 2018.

GRISA, Catia; CALDAS, Eduardo de Lima; ÁVILA, Mario Lúcio de. As compras públicas da agricultura familiar no Brasil: de onde veio essa ideia? In: SABOURIN, Eric; GRISA, Cátia (Orgs.). A difusão de políticas brasileiras para a agricultura familiar na América Latina e Caribe. Brasil: Escritos, 2018.

GRISA, Catia; SCHMITT, Claudia Job. The Food Acquisition Program in Brazil: contributions to biodiversity, food Security and nutrition. In: HUNTER, Danny; BORELLI, Teresa; MATTEI, Federico; FANZO, Jessica (Orgs.). Diversifying food and diets: using agricultural biodiversity to improve nutrition and health. 1. ed. Londres; Nova York: Routledge, 2013. p. 355-361.

GRISA, Catia; SCHMITT, Claudia Job; MATTEI, Lauro Francisco; MALUF, Renato Sergio; LEITE, Sergio Pereira. O Programa de Aquisição de Alimentos (PAA) em perspectiva: apontamentos e questões para o debate. Retratos de Assentamentos, Araraquara, n. 13, n. 1, p. 137-170, 2010. Disponível em: https://retratosdeassentamentos.com/index.php/retratos/article/view/69. Acesso em: 13 mar. 2021.

GRISA, Catia; SCHNEIDER, Sergio. Três gerações de politicas publicas para agricultura familiar e formas de interação entre sociedade e estado no Brasil. Revista de Economia e Sociologia Rural, Brasília, v. 52, supl. 1, p. 125-146, 2014. Disponível em:

https://www.revistasober.org/article/doi/10.1590/s0103-20032014000600007. Acesso em: 2 mar. 2021.

GUPTA, Devashree. The power of incremental outcomes. How victories and defeats affect social movements organizations. Mobilization, v. 14, n. 4, p. 417-432, 2009.

HENRICHS, Joanni Aparecida; MEZA, Maria Lúcia Figueiredo Gomes de. Governança multinível para o desenvolvimento regional: um estudo de caso do Consórcio Intermunicipal da Fronteira. Revista Brasileira de Gestão Urbana, Curitiba, v. 9, n. 1, p. 124-138, 2017.

KROTH, Darlan Christiano; ZONIN, Valdecir José; COLETTI, Tomé; SIMÕES, William; VON DENTZ, Eduardo. Análise da operacionalização da política de aquisição de alimentos da agricultura familiar por parte dos municípios: o caso do PNAE em três microrregiões do Oeste Catarinense. Redes, Santa Cruz do Sul, v. 24, n. 1, p. 138-162, 2019.

MATTEI, Lauro. O governo interino e a desestruturação da política agrária e de desenvolvimento rural no país. Texto para discussão 18. Florianópolis: Necat, 2016. 
MOLINA, Wagner de Souza Leite; BEZERRA, Islandia; ROZENDO, Cimone; BASTOS, Fernando. Práticas e mecanismos de inovação na construção de mercados para a agricultura familiar. In: SCHNEIDER, Sergio; MENEZES, Marilda; SILVA, Aldenor Gomes da; BEZERRA, Islandia (Orgs.). Sementes e brotos da transição: inovação, poder e desenvolvimento em áreas rurais do Brasil. 1. ed. Porto Alegre: Editora da UFRGS, 2014. p. 193-214.

MOURA, Joana Tereza Vaz de; MOREIRA, Ivaldo de Sousa; GOMES, Sandra. Gestão participativaterritorial como parte de arranjos institucionais indutores da efetividade: um estudo de caso de dois Colegiados Territoriais. Redes, Santa Cruz do Sul, v. 22, n. 3, p. 65-93, 2017. Disponível em: https://online.unisc.br/seer/index.php/redes/article/view/9946.

Acesso em: 17 fev. 2021.

NARDINI, Monica; SOUZA, Eduardo Garcia; SACCO DOS ANJOS, Flávio. Os dilemas do desenvolvimento rural: um olhar para o rural. Revista Desenvolvimento Socioeconômico em Debate, Criciúma, v. 5, n. 1, 2019. Disponível em:

http://periodicos.unesc.net/RDSD/article/view/4908. Acesso em: 28 mar. 2021.

PISMEL, Adriana Cattai. Atuando nas fronteiras: o MST e a implementação do Programa de Aquisição de Alimentos na Região Metropolitana de Campinas. In: ENCONTRO INTERNACIONAL PARTICIPAÇÃO, DEMOCRACIA E POLÍTICAS PÚBLICAS, 3., Vitória, 2017. Anais... Vitória: UFES, 2017.

POLLETTA, Francesca. It was like a fever: storytelling in protest and politics. Chicago: The University of Chicago Press, 2006.

RECH, Carla Michele; SILVA, Marcelo Kunrath. Ativismo institucional como categoria analítica para o estudo das práticas políticas dos movimentos sociais no Brasil. In: SEMINÁRIO NACIONAL DE SOCIOLOGIA DA UFS, 1., São Cristóvão, 2016. Anais... São Cristóvão: PPGS/UFS, 2016. p. 375-388.

REIS, Rafael Moraes. Governança multinível dos recursos hídricos para adaptação às mudanças climáticas: o caso da Câmara Consultiva Regional do Submédio São Francisco. 2019.189 f. Dissertação (Mestrado em Desenvolvimento Sustentável) - Universidade de Brasília, Brasília, 2019. Disponível em: https://repositorio.unb.br/handle/10482/37971. Acesso em: 10 jun. 2021.

ROZENDO, Cimone; BASTOS, Fernando; MOLINA, Wagner de Souza Leite. Desafios institucionais para a inclusão da agricultura familiar no Programa Nacional de Alimentação Escolar. Cronos, Natal, v. 14, n. 2, p. 23-35, 2013. Disponível em: https://periodicos.ufrn.br/cronos/article/view/6335. Acesso em: 29 jan. 2021.

ROZENDO, Cimone. Limites e possibilidades dos circuitos curtos enquanto estratégia de desenvolvimento: o caso do Programa de Aquisição de Alimentos em Apodi/RN. In: ENCONTRO ANUAL DA ANPOCS, 41., Caxambu, 2017. Anais... Caxambu: Anpocs, 2017.

SAMBUICHI, Regina Helena Rosa et al. Programa de Aquisição de Alimentos e Segurança Alimentar: modelo logico, resultados e desafios de uma política pública voltada para o fortalecimento da agricultura familiar. Texto para Discussão. Brasília: Ipea, 2019. Disponível em: http://repositorio.ipea.gov.br/bitstream/11058/9319/1/TD_2482.pdf. Acesso em: 11 fev. 2021. SEN, Amartya. Desenvolvimento como liberdade. São Paulo: Companhia das Letras, 2000.

SILVA JÚNIOR, Marcos Aurélio Freire da; NASCIMENTO, Shesby André; MOURA, Joana Tereza Vaz de. O limite difuso entre militante e gestor: um estudo sobre o ativismo institucional no Governo do Rio Grande do Norte, Brasil. Revista Brasileira de Políticas Públicas e Internacionais, João Pessoa, v. 5, n. 2, p. 290-310, 2020. Disponível em: https://periodicos.ufpb.br/index.php/rppi/article/view/51095. Acesso em: 26 fev. 2021. 
SILVA, Marcelo Kunrath. Associativismo Comunitário em Porto Alegre: repertórios de ação e configurações políticas locais. In: LÜCHMANN, Lígia; GUSSO, Ramon (Orgs.). Estudos sobre o associativismo no Sul do Brasil. 1. ed. Curitiba: Appris, 2021. p. 197-229.

TATAGIBA, Luciana; ABERS, Rebecca Neaera; SILVA, Marcelo Kunrath. Movimento sociais e políticas públicas: ideias e experiências na construção de modelos alternativos. In: PIRES, Roberto; LOTTA, Gabriela; OLIVEIRA, Vanessa Elias de (Orgs.). Burocracia e políticas públicas no Brasil: interseções analíticas. Brasília: Ipea; Enap, 2018. p. 106-138.

TARROW, Sidney. O poder em movimento. Movimentos sociais e confronto político. Petrópolis: Vozes, 2009.

\section{Como citar}

MOURA, Joana Tereza Vaz de; KNOX, Winifred; SILVA JÚNIOR, Marcos Aurélio Freire da. Os efeitos dos movimentos rurais e das oportunidades políticas na construção do programa de compras governamentais do Rio Grande do Norte. Estudos Sociedade e Agricultura, Rio de Janeiro, v. 29, n. 3, p. 727-749, out. 2021. DOI: https://doi.org/10.36920/esa-v29n3-9. 